\title{
Carácter adquirido, autodominio y moralidad: hacia una mirada comprehensiva de la filosofia práctica schopenhaueriana
}

\author{
Luciana Samamé \\ Universidad Yachai Tech
}

Resumen: Entre el amplio espectro de cuestiones que han puesto en movimiento la pluma filosófica de Arthur Schopenhauer, la cuestión del carácter reclama, sin dudas un lugar significativo. Este artículo ofrece una reflexión sobre un concepto de vital importancia para su filosofia práctica: el de "carácter adquirido". En opinión de nuestro autor, adquirir carácter no importa tanto desde un punto de vista ético cuanto prudencial. Esta aseveración puede, con todo, ser desafiada si consigue mostrarse que al adquirir carácter, un sujeto desarrolla el mismo tipo de habilidad requerida para actuar en sentido moral. Semejante linea argumentativa será seguida en este trabajo, al tiempo que intentará volverse consistente la propia posición asumida por Schopenhauer. Creemos que una lectura así orientada tiende a promover una interpretación más unitaria de su filosofia práctica.

Palabras clave: Schopenhauer; ética; virtud; prudencia; razón práctica

\begin{abstract}
Acquired Character, Self-Control and Morality: Towards a Comprehensive View of Schopenhauerian Practical Philosophy". Among the wide range of issues that have drawn Schopenhauer's attention, the issue of character undoubtedly plays a decisive role. In this paper, I will focus on an essential concept for his practical philosophy: the concept of "acquired character." In Schopenhauer's view, to acquire character is a matter of prudence rather than morality. Despite of this assertion, I will attempt to challenge Schopenhauer's statement, by arguing that acquiring character actually involves moral meaning. This moral implication arises from a point of view that is internal to Schopenhauer's practical philosophy taken as a whole. Consequently, I will try to make his account consistent by appealing to his own arguments.
\end{abstract}

Keywords: Schopenhauer; ethics; virtue; prudence; practical reason 


\section{Introducción}

Durante las últimas décadas, la llamada ética de la virtud ha venido experimentando de manera constante y creciente una expansión formidable. Es así como la discusión contemporánea ha vuelto a poner en el centro del escenario moral las nociones de "vida buena", "virtud" y "carácter" antes que las de "obligaciones", "reglas" o "acciones" énfasis, hay quienes actualmente prefieren tematizar las evaluaciones morales en términos de agentes y no tanto de acciones. En tal contexto, no resulta para nada irrelevante prestar atención al fino desarrollo que Schopenhauer urde en torno a la cuestión del carácter humano. De hecho, su teoría ética puede interpretarse en clave aretaica ${ }^{2}$, al estar fuertemente centrada en la noción de virtud antes que en la de obligación o consecuencias.

En lo que a materia ética concierne, Schopenhauer asume como punto de partida la distinción kantiana entre moralidad y prudencia. Con esta distinción en miras, afirma que la importancia del carácter adquirido descansa en su potencial prudencial, esto es, en su capacidad contributiva al bienestar o felicidad del agente. Por este motivo, es incapaz de auspiciar o fortalecer la disposición moral de este último: el filósofo de Frankfurt parte de la distinción conceptual inflexible entre felicidad y virtud, que se traduce asimismo en la

1 Cf. Amaya, A. y H. Lai, Law, Virtue and Justice, Oregon: Hart Publishing, 2013, p. 1.

2 Estudiosos contemporáneos de la ética de Schopenhauer resaltan su fuerte parentesco con la perspectiva teórica asumida por las éticas de la virtud. David Cartwright, por ejemplo, sostiene que Schopenhauer debería ser reconocido como uno de los antecesores filosóficos de la actual reevaluación de la "filosofia moral moderna" ( $c f$. Cartwright, D., "Schopenhauer's Narrower Sense of Morality", en: Janaway, C. (ed.), The Cambridge Companion to Schopenhauer, Cambridge: Cambridge University Press, 2006, p. 255). Richard Taylor, quien aboga abiertamente por un retorno a la ética de la virtud, asevera que el efecto de Über das Fundament der Moral sobre su propia filosofia ha sido más profundo que el de cualquier otra obra ( $c f$. Taylor, R., Good and Evil. A Forceful Attack on the Rationalistic Tradition in Ethics, Nueva York: The Macmillan Company, 1970, p. XIII). Por lo demás, Atwell señala que Schopenhauer enumera prácticamente la mayoría de las críticas efectuadas a la ética kantiana durante los últimos doscientos años, muchas de las cuales fueron más tarde enfatizadas por teóricos de la virtud contemporáneos: 1) que una concepción legalista de la ética deriva del pensamiento moral judeo-cristiano, de modo que nociones tales como las de "ley moral" y "obligación" solo tienen sentido a la luz de un legislador dispensador de premios y castigos; 2) que los imperativos no pueden ser nunca categóricos, sino siempre hipotéticos; 3) que el incentivo moral no se identifica en absoluto con el puro respeto por la ley moral; 4) que Kant introduce de manera confusa la noción de "bien supremo"; etcétera. (cf. Atwell, J., Schopenhauer. The Human Character, Filadelfia: Temple University Press, 1990, p. 91). 
oposición tajante entre egoísmo y altruismo, o entre prudencia y moralidad. Luego, como el hecho de adquirir carácter redunda en la felicidad del agente, no puede a la postre enfundar prestancia moral.

Con todo, parece haber un importante sentido en que la teoría del carácter adquirido afecta a la moralidad. Si estamos en lo cierto, tendría que existir alguna clase de enlace capaz de unir esos ámbitos -los de moralidad y prudencia- que Schopenhauer ha separado en principio. En esto consistirá precisamente la estrategia argumentativa que aquí se seguirá: en hacer tangible la presencia de una noción común a ambas esferas. A nuestro entender, dicha noción es la de autodominio, ya que opera de manera central tanto en la esfera moral como en la prudencial. Teniendo en cuenta esta hipótesis medular, el presente trabajo adoptará la siguiente estructuración: en primer lugar, se expondrá la doctrina schopenhaueriana del carácter adquirido, evidenciando en ese contexto la centralidad de la noción de autodominio; en segundo lugar, se intentará visibilizar el papel fundamental que dicha noción también desempeña en el marco de su teoría de la virtud, particularmente en relación con la virtud de la justicia; en tercer lugar, si la hipótesis que aquí proponemos es correcta, habria buenas razones para afirmar que, desde la óptica schopenhaueriana, la persona que adquiere carácter desarrolla a un tiempo una aptitud para la moralidad, al ejercitar y perfeccionar el mismo tipo de disposición que esta última requiere.

\section{La doctrina del carácter adquirido}

Es indudable que la cuestión del carácter ocupa un lugar destacado en el corpus filosófico schopenhaueriano. Su tratamiento del tema reviste tal importancia y originalidad que ameritaria una investigación completa ${ }^{3}$. Algunos incluso han llegado a afirmar que su sistema filosófico erige en su mismo centro a la doctrina del carácter ${ }^{4}$. Por lo demás, las obras respectivas donde Schopenhauer despliega en forma más o menos pormenorizada su teoría del carácter, son: El mundo como voluntad y representación, Sobre la libertad de

\footnotetext{
3 Quizás uno de los estudios más exhaustivos e interesantes sobre el tema sea el que Atwell ofrece en su libro Schopenhauer. The Human Character, un libro que a los presentes propósitos nos ha resultado de utilidad incomparable y al que se hará referencia una y otra vez a lo largo de este trabajo.

4 Cf. Koßler, M., "Life is But a Mirror: On the Connection Between Ethics, Metaphysics and Character in Schopenhauer”, en: Janaway, C. y A. Neil (eds.), Better Consciousness. Schopenhauer's Philosophy of Value, Reino Unido: Blackwell Publishing, 2009, p. 78.
} 
la voluntad y Sobre el fundamento de la moral. La referencia a ellas se vuelve por ello forzosa.

Antes de abordar el tema en cuestión, es preciso mencionar que la teoría schopenhaueriana del carácter (Charakter) es ininteligible al margen de su metafisica, puesto que el carácter específico de cada entidad natural es remitido originariamente a la voluntad, principio metafisico responsable del mundo y la existencia. En forma rudimentaria, puede adelantarse que el carácter consiste en la configuración especial que la voluntad (Wille) alcanza en sus distintas manifestaciones fenoménicas ${ }^{5}$, lo que hace a cada cosa ser propiamente lo que es. En la naturaleza, luego, todo posee fuerzas y cualidades definidas mediante las que se reacciona de modo específico ante determinada influencia ${ }^{6}$ y que constituyen justamente su carácter ${ }^{7}$. Schopenhauer considera que a mayor perfección alcanzada por cada objetivación de la voluntad, mayor grado de singularidad consigue expresar su carácter. Mientras que entre los animales no-humanos el carácter varía de especie en especie, entre los humanos, en cambio, lo hace de individuo a individuo. Como, a juicio del filósofo alemán, estos últimos representan "la manifestación más perfecta de la voluntad", es prerrogativa suya la posesión de un carácter individual: "Esta índole especial e individualmente determinada de la voluntad, en virtud de la cual su reacción a los mismos motivos es distinta en cada hombre, constituye aquello a lo que

5 Bajo el influjo de la filosofia trascendental kantiana, Schopenhauer suscribe la distinción entre fenómeno y cosa en sí aunque, a diferencia de Kant, llega a identificar positivamente a la última con la voluntad. Todo fenómeno es luego en su óptica manifestación empírica de un único principio metafisico fuera del tiempo, el espacio y la causalidad, al que Schopenhauer denomina "Wille", un impulso ciego hacia la existencia. En este sentido, la voluntad como potencia metafísica se ubica en las antípodas de la concepción clásica de la voluntad como potencia racional y consciente. Es dable decir que el autor de El mundo como voluntad y representación no solo revierte el significado tradicionalmente asociado al término, sino que va más allá, ampliando su campo semántico: el uso del concepto "voluntad", lejos de restringirse al ámbito humano, se extiende hacia la totalidad de lo existente. Desde esta perspectiva, todo lo que existe constituye la expresión espacio-temporal de la voluntad metafisica.

6 Esta influencia externa puede obedecer a una tipología triple, según la clase de ser sobre la que se aplique: si se ejerce sobre el reino inorgánico, se llama "causalidad"; si lo hace en cambio sobre el reino vegetal, "estimulo"; finalmente, si se trata de la influencia ejercida sobre el animal, 128 se denomina "motivación" ( $c f$. Schopenhauer, A., "Sobre la libertad de la voluntad", en: Schopenhauer, A., Los dos problemas fundamentales de la Ética, López de Santa María, P. (trad.), Madrid: Siglo XXI Editores, 2002, pp. 58-64. De aquí en adelante " $L V$ ".

7 Cf. Schopenhauer, A., El mundo como voluntad y representación, v. I, Aramayo, R. (trad.), Madrid: FCE, 2005, p. 382 (§55). De aquí en adelante "MVR $P$ ".

$8 \quad$ Ibid., p. 382 (\$55). Lógicamente, es dable preguntarse por qué Schopenhauer concibe al ser humano como la consumación más perfecta de la voluntad. Para nuestra sorpresa, la respuesta que proporciona no logra distinguirse sustancialmente de la que daria un hegeliano: porque solamente esta clase de criatura es capaz de cobrar plena autoconciencia, al alcanzar un conocimiento claro de la propia esencia que también se manifiesta en el mundo. 
se llama su carácter y, por cierto, carácter empírico, ya que no es conocido a priori sino solo por experiencia [durch Erfahrung]"9.

En virtud de la descripción precedente, el carácter humano es definido por las siguientes notas: 1) es individual, ya que la combinación de las distintas cualidades morales se da de manera única en cada persona ${ }^{10}$; 2) es empírico, puesto que es dable conocerlo exclusivamente mediante la experiencia, esto es, a través de las distintas acciones que se van ejecutando en el transcurso vital. Como es su costumbre hacer, Schopenhauer postula para cada una de sus proposiciones, un correlato metafísico. Es así como el carácter empírico constituye en su opinión la instanciación espacio-temporal del carácter inteligible.

Al sentar esta distinción -nos dice en su obra principal-, no hace más que seguir aquella misma establecida por Kant entre carácter inteligible y empírico ${ }^{11}$, por la cual se llega a identificar al primero con la cosa en sí, y al segundo con su manifestación fenoménica ${ }^{12}$. Consecuentemente, nuestro filósofo asevera que el carácter inteligible es la expresión libre y extratemporal de la voluntad, cuyo despliegue a partir de las coordenadas de espacio, tiempo y causalidad conforma el carácter empírico; este se infiere, por tanto, de la suma total de los actos de un individuo ${ }^{13}$. Bajo este encuadre, las acciones ejecutadas a lo largo de un determinado transcurso vital, pueden concebirse en cuanto reiterada expresión del carácter inteligible, de la misma forma en que un árbol es la constante manifestación de un único impulso que puede reconocerse tanto en la fibra y en la hoja, como en el tallo, la rama y el tronco ${ }^{14}$.

A las dos notas del carácter humano recién referidas, cabe todavía agregar otras dos, en función de las cuales asimismo es ${ }^{15}$ : 3) constante, es decir, permanece idéntico durante toda la vida; con ello desea indicarse que, a pesar de las modificaciones introducidas por los años, las circunstancias, e incluso

\footnotetext{
9 Schopenhauer, A., $L V$, p.79.

10 Schopenhauer identifica así al carácter con el carácter moral: al mentar el carácter de una persona, aquel está pensando principalmente en la peculiar configuración y combinación que los distintos motivos morales adquieren en ella.

${ }^{11}$ Kant expone esta teoría en la Crítica de la razón pura (A 532-B 560ss) y en la Crítica de la razón práctica (Ak. V, 95-100).

${ }^{12}$ Cf. Schopenhauer, A., MVR I, p. 384 (§55).

${ }^{13}$ Tal como señala Koßler (cf. o.c., p. 80), el carácter de una persona puede ser inferido, hasta un cierto punto, de la observación empírica. Sin embargo, al ser solamente derivable por medio de observaciones fragmentarias, existe una diferencia no eliminable entre carácter empírico e inteligible pues este último debe ser entendido como una condición constantemente determinada.

${ }^{14}$ Cf. Schopenhauer, A., MVR I, p. 385 (§55).

15 Cf. Schopenhauer, A., LV, pp. 79-93, donde Schopenhauer explicita estas cuatro cualificaciones del carácter humano.
} 
los conocimientos, un ser humano "no cambia jamás"; 4) innato, pues no se trata del fruto del arte ni de circunstancias fortuitas, sino de la naturaleza. Así -concluye problemáticamente el filósofo de la voluntad-, vicios y virtudes son también innatos.

Con estas cualificaciones se completa el trazado del carácter humano. Es menester advertir, tal como lo hace Atwell, que el mismo es concebido por Schopenhauer principalmente en términos morales, antes que en términos de "personalidad"16. Tal cosa se patentiza sobre todo a partir de las últimas cualidades descritas, con las que pretende referirse que, aquello que de invariable posee una persona es su talante moral, y que no es éste fruto de la instrucción sino de la naturaleza.

Ahora bien, a la distinción anteriormente aludida entre carácter inteligible y carácter empírico, se le añade una tercera categoría, la del carácter adquirido (erworbenen Charakter), puntualizada con las siguientes palabras: "Este [el carácter adquirido] no es otra cosa que el conocimiento más perfecto posible de la propia individualidad; se trata de un saber abstracto y claro acerca de las propiedades inalterables de su propio carácter empírico, así como de la proporción y orientación de sus propias fuerzas corporales y espirituales, en una palabra, de la fortaleza y las debilidades de la propia individualidad. Esto nos coloca en situación de ejecutar reflexiva y metódicamente el rol -inmodificable de suyo- de la propia persona, que veníamos ejecutando de un modo naturalizado e irregular, rellenando mediante la guía de conceptos firmes las lagunas que ocasionaban los caprichos y las flaquezas" ${ }^{17}$.

Llamativamente, adquirir carácter no significa -tal como la expresión misma sugiere- forjarse un nuevo carácter (ya que sería contradictorio con la tesis de la innatez e inmodificabilidad del carácter). Para Schopenhauer, "adquirir carácter" no significa otra cosa que alcanzar un íntegro autoconocimiento: su adquisición se hace posible mediante nuestro trato con el mundo durante una vida entera. Es en esta dirección que se elogia, ciertamente, a la persona con carácter, en tanto se censura a la que carece de él ${ }^{18}$. Si bien todos poseemos un carácter, no todos poseemos carácter y en opinión del filósofo alemán, las personas suelen normalmente desconocerse a sí mismas. Cada una ejecuta en forma prácticamente instintiva su carácter empírico, por lo que llegar a comprenderse, saber aquello que se quiere y se ajusta a la propia personalidad,

${ }^{16}$ Cf. Atwell, J., o.c., p. 38.

17 Schopenhauer, A., MVR I, p. 400 (§55). El énfasis es nuestro.

18 Ibid., p. 398 (§55). 
es tarea bien difícil. Como podrá advertirse, la noción de "carácter adquirido" no connota ya simplemente el talante moral del agente, sino algo más complejo, identificable en buena medida con su individualidad. Esta abarca también los talentos naturales y los diferentes rasgos de personalidad. De manera que el gnothi seautou mentado por Schopenhauer, involucra el conocimiento del conjunto de las propias cualidades fisicas, morales e intelectuales.

Se ha indicado con anterioridad que la valía implicada en semejante autoconocimiento radica en su contribución a la felicidad del sujeto. A este respecto, el autor de los Parerga afirma que aquel que desconoce su propia individualidad, se acarrea el más amargo de los sufrimientos: el descontento consigo mismo. Reproducimos a continuación este largo pasaje, el cual condensa reveladoras ideas: "Al conocer la indole y la medida de nuestras fuerzas y nuestras flaquezas, nos ahorraremos muchos disgustos. Pues en realidad no hay goce alguno al margen del uso y disfrute de las propias fuerzas, y no hay mayor dolor que percibir la falta de dichas fuerzas alli donde se las precisa. Al indagar donde se hallan nuestra fortaleza y nuestras flaquezas, cultivaremos nuestras disposiciones naturales más sobresalientes, intentando rentabilizarlas de todos los modos posibles, para aplicarlas allí donde sirvan y valgan más; gracias al autodominio [Selbstüberwindung] eludiremos aquellos afanes para los que por naturaleza tenemos escasas disposiciones y desistiremos de intentar aquello que no se nos da bien. Solo quien logra esto será continuamente él mismo por completo con plena reflexión y nunca se dejará en la estacada de suyo, al saber siempre lo que puede exigirse a sí mismo"19.

Schopenhauer asevera con firmeza que al desconocerse a sí mismo, uno se asegura cierta dosis de malestar y descontento. De allí la necesidad de su reversión a los fines de la propia felicidad. Tal desconocimiento puede tener su origen en diversos factores: la falta de reflexividad y también a veces su presencia. En el primer caso, porque nos dejamos arrastrar por impresiones presentes que nos llevan a efectuar acciones incongruentes con nuestras disposiciones, lo cual genera frustración y arrepentimiento. En el segundo caso, porque nuestra razón suele mostrarnos lo que incumbe al ser humano en general, en dirección a todo aquello que puede quererse y efectuarse conforme al carácter de la especie. Las posibilidades de cada individuo son, sin embargo, mucho más limitadas, en la medida en que puede realizar solamente un afán con tesón y fortuna, se

${ }^{19}$ Ibid., p. 401 (§55). El énfasis es nuestro. 
trate del honor, la riqueza, la ciencia, el arte o la virtud ${ }^{20}$. Para contrarrestar ambas flaquezas, nacidas tanto de la irreflexibilidad como de su opuesto, Schopenhauer aboga por la práctica del autodominio -Selbstüberwindung-21, que tiene como condición necesaria el autoconocimiento.

Sentado esto, es preciso interrogarse en qué consiste el autoconocimiento para nuestro autor. La introspección resulta inútil en su óptica, al haber establecido que el propio carácter solamente se conoce por experiencia, esto es, mediante aquellas acciones efectuadas en el transcurso vital ${ }^{22}$. Como además cree que tales acciones representan la expresión del carácter inteligible, uno debería ser capaz de leer ese elemento común que alienta en todas ellas: hay fines que buscamos invariablemente, aunque a veces sin saberlo y en formas poco concordantes con nuestras capacidades. Una vez reconocido eso que se quiere y que es factible ejecutar según las propias fuerzas, pero asimismo también aquello otro fuera de nuestro alcance, entonces se ha logrado en grado óptimo el conocimiento de sí. Como consecuencia, ya no consiguen seducirnos fácilmente las impresiones fugaces, ni tampoco los numerosos arquetipos y metas que la razón nos presenta como posibles (posibles para el ser humano en general, pero no para cada uno en particular) ${ }^{23}$.

En esta dirección, Robert Wicks ofrece una interpretación sumamente interesante de la teoría del carácter adquirido, al ponerla en conexión con la

20 Ibid., p. 399 (§55).

21 La idea de que la filosofia schopenhaueriana pueda albergar la posibilidad del autodominio es problemática. Principalmente, porque no es la razón sino la voluntad la que establece los fines, siendo quien primariamente nos domina y constituye. Esto significa que no está en nuestro poder elegir lo que somos, los fines hacia los que tendemos, o en otros términos, aquello que queremos y por lo que nos esforzamos. "El querer no se elige" -dice el filósofo de la voluntad siguiendo a Séneca-. Nuestro carácter inteligible es en efecto un acto libre de la voluntad y Schopenhauer niega rotundamente por ello que uno escoja su modo de ser. Con todo, la idea de autodominio no deja de tener sentido en ese contexto: si bien no está al alcance de los individuos la posibilidad de cambiar su carácter, sí lo está la capacidad de orientar sus afanes en función de esa base inalterable, como asimismo la de rechazar ciertos propósitos incongruentes con los propios fines. El autodominio, por consiguiente, se ejercita dentro de los inamovibles márgenes de lo que se es.

22 Dado que el propio carácter puede tan solo ser conocido a través de la experiencia, es preciso adoptar frente al mismo el punto de vista de un observador externo, al tratarse sin dudas de un

132 objeto para un sujeto. De ello se desprende, paradójicamente, que no nos podemos conocer a nosotros mismos mejor de lo que podríamos conocer a otras personas. Schopenhauer admite tácitamente esta posibilidad al afirmar que el carácter, trátese del propio o de uno ajeno, se conoce únicamente mediante la experiencia.

${ }^{23}$ Es interesante notar que este fin del que depende la realización personal, está dado por el carácter individual y no por el de la especie. Es así como la felicidad deja de ser prioritariamente definida en función de fines genéricos que atañerian a toda criatura en cuanto miembro de la misma especie. Este se trata sin dudas de un aspecto importantísimo en el que Schopenhauer se aparta de la tradición racionalista, y que se explica en buena parte por su negativa a delimitar la esencia humana en el elemento racional. 
teoría estética de Schopenhauer: así como el genio artístico aprehende las esencias universales en los objetos individuales, aquel que adquiere carácter aprehende su personalidad a través de sus actos singulares. De manera que este último lanza sobre sí mismo la mirada del genio artístico, discierne aquello que está llamado a ser y deviene su propio genio. Wicks lleva la analogía un poco más lejos: al igual que la obra de arte expresa la idea platónica con mayor claridad que los objetos cotidianos, el individuo con carácter exhibe con mayor profundidad su carácter inteligible y por eso su vida se convierte en una obra de $\operatorname{arte}^{24}$.

Al haber contemplado la cualidad de su subjetividad, la persona que adquiere carácter sabe quién es, posee un norte y es en consecuencia honesta consigo misma: ahora interpreta concienzuda y metódicamente el propio papel, que el carácter empírico simplemente naturalizaba ${ }^{25}$. De esto proviene un sentido de auto-realización y auto-perfección, vinculado con la práctica de autodominio: quien se conoce a sí mismo, se sujeta a la guía de "conceptos firmes" y de "principios generales" que la razón le presenta ${ }^{26}$, conceptos y principios que esta última infiere de la experiencia. Con base en un conjunto de acciones previamente ejecutadas, la razón va extrayendo máximas generales que le permitirán al sujeto orientarse en el futuro. Si por ejemplo una persona, tras haber realizado numerosos viajes, se percata de la inmensa satisfacción que tales experiencias le han procurado, extraerá de ellas la máxima general "viajar me hace feliz". Luego, esta máxima le servirá para tomar decisiones futuras relativas a situaciones particulares: "voy a ahorrar dos meses de mi sueldo para poder visitar Marruecos el próximo verano".

Con arreglo a los desarrollos precedentes, puede establecerse la siguiente conclusión: no es factible adquirir carácter al margen de un cabal conocimiento de sí. En líneas generales, Schopenhauer lo consigna como el conocimiento de aquello que propiamente se quiere y de lo que uno es capaz. Ahora bien -y aquí arribamos al punto que nos interesa resaltar convenientemente-, este auto-conocimiento permitirá el potenciamiento de una destreza en particular, la de dominarse a sí mismo, porque al saberse de una vez por todas aquello que se quiere y de que se es capaz, "ante cualquier opción solo hemos de aplicar principios universales a casos concretos para adoptar una decisión”27.

\footnotetext{
${ }^{24}$ Cf. Wicks, R., Schopenhauer, Singapore: Blackwell Publishing, 2008, pp. 119-121.

${ }^{25}$ Cf. Schopenhauer, A., $L V$, p. 81.

${ }^{26}$ Cf. Schopenhauer, A., MVR I, p. 401 (§55).

27 Ibid. El énfasis es nuestro.
} 


\begin{abstract}
Esto significa que tales principios nos auxiliarán en aquel tipo de casos donde ciertos deseos o metas nos impulsen hacia direcciones poco congruentes con el propio modo de $\operatorname{ser}^{28}$. Como consecuencia, el individuo alcanzará una buena medida de autarquía ${ }^{29}$ y de felicidad ${ }^{30}$.
\end{abstract}

\title{
III. Moralidad, carácter y virtud
}

Se ha mencionado que Schopenhauer asegura, al referirse al carácter adquirido, que este no importa tanto a la ética en sentido estricto (eigentliche Ethik) como a la vida mundana (Weltleben) ${ }^{31}$. Ello es así porque aquel establece

\footnotetext{
${ }^{28}$ Si por caso, y para seguir con el ejemplo anterior, la misma persona se ve tentada de comprar un costosísimo diseño de Oscar de la Renta mientras observa una vidriera -sin tener afición por la alta costura y todavía a sabiendas de las escasas oportunidades que tendrá de usarlo por no frecuentar distinguidos círculos-, la máxima "viajar me hace feliz" y el pensamiento relativo al plan de destinar ahorros para visitar Marruecos, actuarán como "frenos" de ese impulso inmediato y un tanto irracional.

${ }^{29}$ Con su doctrina del carácter adquirido Schopenhauer sugiere que no se trata tanto de poseer tales o cuales condiciones, tampoco de gozar de cierto renombre, rango, honor o fortuna. Se trata, simplemente, de conocer las propias aptitudes y saber emplearlas con destreza. El paralelo con el "espiritu" de las escuelas helenísticas es en este punto sorprendente: el arte de vivir helenístico también se caracterizaba por proponer hacer el mejor uso posible de sí mismo, en cualesquiera circunstancias ( $C f$. Long, A., From Epicurus to Epictetus. Studies in Hellenistic and Roman Philosophy, Oxford: The Clarendon Press, 2006, p. 27). No parece forzado concluir que la teoría del carácter adquirido en Schopenhauer, viene a ser otra forma de expresar el ideal helenístico de autarquía. Con arreglo a ello, no es nada casual que cite las palabras empleadas por Cicerón y Séneca, "omnia mea mecum porto" (todos los bienes los llevo en mí) y que reconozca abiertamente que bastarse a sí mismo, es la condición que mayormente favorece a nuestra felicidad $(C f$. Schopenhauer, A., Parerga y Paralipomena I, López de Santa María, P. (trad.), Madrid: Trotta, 2006, p. 434). Por ejemplo Séneca nos da muestras de similar pensamiento: "Todos estamos ligados a la fortuna... A uno lo encadenan los honores, a otro las riquezas; a algunos la nobleza los agobia, a otros su humilde origen... De modo que hay que acostumbrarse a la propia condición y quejarse lo menos posible, y tomar de ella todas las ventajas que le rodean" (Séneca, L.A., "Sobre la serenidad", en: Diálogos, Codoñer, C. (trad.), Barcelona: Altaya, 1997, 10, pp. 3-4).

${ }_{30}$ Dado que Schopenhauer propugna una concepción negativa de felicidad -como aquella condición exenta de dolor- ser feliz consistirá en no ser infeliz. La infelicidad asume básicamente dos formas básicas según el filósofo de la voluntad: el dolor y el aburrimiento. Precisamente, quien se conoce a sí mismo y adquiere carácter, toma posesión del arma más poderosa con la que hacer frente a estos dos flagelos humanos. El agente que conoce, por un lado, sus propios talentos, capacidades o disposiciones, procurará realizar solamente aquellas actividades convenientes a

134 las mismas, escogiendo la profesión o tarea que mejor le cuadre; por esta via, se pone a resguardo del aburrimiento, puesto que al encontrarse satisfacción en el uso de las propias fuerzas, en la ejecución de cierta actividad, se precave adecuadamente ante el abatimiento existencial en el que nada conseguiria motivarle. Por otro lado, quien logra ese cabal autoconocimiento, se ve llevado a reducir considerablemente sus afanes, al darse cuenta de que solo puede realizar con éxito muchos menos; de este modo, se salvaguarda del malestar inherente a la voracidad del deseo. Si uno consigue resguardarse así tanto del dolor como del aburrimiento, su transcurso vital adquirirá los contornos de una existencia despreocupada y tranquila, exenta tanto de grandes molestias como de desidia.
}

${ }^{31}$ Cf. Schopenhauer, A., MVR I, p. 403 (§55). 
-recordemos- una distinción aguda entre moralidad y prudencia: mientras la última concierne a la esfera de la felicidad personal, la primera alude a nuestro trato justo y compasivo con los otros. Dado que adquirir carácter impacta en nuestro bienestar personal, parece en el fondo obedecer a una motivación de tipo prudencial o egoísta, y en virtud de ello, carente de valor moral. Para comprender mejor esta última idea, nos detendremos en el bosquejo de la filosofia moral schopenhaueriana, en cuyo centro anida un fuerte compromiso con la noción de virtud.

Schopenhauer concibe a la teoría ética en términos esencialmente descriptivos, por lo que su principal tarea consiste a sus ojos en analizar las disposiciones presentes en la naturaleza humana, aquellas que la mueven en una dirección o en otra. Tales disposiciones -estrechamente atadas al tipo de motivaciones capaces de incitar a un agente dado- se explican en última instancia por su carácter. Adicionalmente, Schopenhauer postula una suerte de moralidad de la intención (Moralität der Gesinnung) ${ }^{32}$. Acordando en ello con Kant, sostiene que el valor de la acción no puede medirse en función de sus consecuencias, sino más bien por el tipo de motivación que la anima ${ }^{33}$.

Por otro lado, y en franca oposición a Kant, Schopenhauer pretende fundar la moral sobre bases empíricas: a su juicio, la posibilidad de que un acto comporte indudable significación moral, queda demostrada si logra determinarse la existencia de un cierto tipo de acciones, a saber, aquellas que tienen como fuente a la compasión (Mitleid). Esta, en su opinión, se trata de un hecho innegable de la conciencia humana, la cual se aloja en su misma naturaleza y es por ello "originaria e inmediata". De ahí que la persona exenta de compasión sea llamada "inhumana", siendo por lo demás "humanidad" sinónimo de compasión $^{34}$.

Elementalmente, la compasión consiste en toda predisposición desinteresada por la que tiende a prestarse auxilio a otros, o cuanto menos, a tenerlos

\footnotetext{
32 Ibid., p. 442 (§62). Cf. también Schopenhauer, A., Sobre el fundamento de la moral, en: Schopenhauer, A., Los dos problemas fundamentales de la Ética, López de Santa María, P. (trad.), Madrid: Siglo XXI Editores, 2002, p. 227 (§14). De aquí en adelante "FM".

${ }^{33}$ Cf. Schopenhauer, A., MVR II, p. 571.

34 Cf. Schopenhauer, A., FM, p. 237 (§17). Como bien lo advierte Cartwright (o.c., pp. 265-266), en lugar de establecerse el fenómeno de la compasión mediante la idea de "punto de vista moral", Schopenhauer lo hace a través de su recusación del escéptico moral, quien niega la existencia de acciones genuinamente compasivas. En función de ello, el filósofo alemán arguye que solamente se dirige a quienes admiten la realidad de tales hechos.
} 
en cuenta ${ }^{35}$. Schopenhauer está así prioritariamente interesado en fundar la moralidad sobre el altruismo, consignando al egoísmo como a su principal, si bien no único, antagonista ${ }^{36}$.

Con arreglo a ello, la moralidad de la acción se determinará por su contribución sentida y espontánea a la remoción del dolor ajeno. A este móvil, el móvil moral por excelencia, se denomina entonces compasión, y a él se le oponen los incentivos anti-morales de egoísmo y crueldad ${ }^{37}$. Con base en esta triple clasificación, Schopenhauer erige su teoria de vicios y virtudes, desarrollada en forma especial en Sobre el fundamento de la moral. Tan pronto establecidos los motivos anti-morales como morales, pasa a deducir de ellos los respectivos vicios y virtudes. Del egoísmo, por ejemplo, inferirá los vicios de injusticia, codicia, gula, orgullo, lujuria y vanidad; mientras que de la maldad, los vicios de envidia, ira, calumnia, odio, venganza, traición, y alegría del mal ajeno ${ }^{38}$.

Por contrapartida, del incentivo de la compasión, se deducen las virtudes cardinales de justicia (Gerechtigkeit) y filantropía (Menschenliebe). De la primera se desprenden a su vez las virtudes de honestidad, diligencia y equidad; de la segunda, las virtudes de benevolencia, caridad y amor. En conjunto, representan el principio supremo de toda moralidad: "Neminem laede; imo omnes, quantum potes, juva", siendo esta la fórmula de la virtud en general ${ }^{39}$. Justicia y filantropía conforman así, aunque a diferente escala, expresiones de idéntico motivo, a saber, la compasión: en el primer caso, contrarrestando motivos egoístas o malvados, refrenándonos de causar sufrimiento a otros seres; en el segundo, impulsándonos en su ayuda activa ${ }^{40}$. Dos son luego los niveles en que opera la compasión: negativamente en el caso de la justicia, positivamente en el de la filantropía o caridad.

\footnotetext{
${ }^{35}$ Esta es la definición de compasión que Schopenhauer nos ofrece (FM, p. 233 (§16)): "El proceso aquí analizado no es imaginario o tomado del aire sino totalmente real y en absoluto infrecuente: es el fenómeno cotidiano de la compasión, es decir, de la participación totalmente inmediata e independiente de toda otra consideración, ante todo en el sufrimiento de otro y, a través de ello, en la obstaculización o supresión de ese sufrimiento, en la que en último término consiste toda satisfacción y todo bienestar y felicidad".

${ }^{36} C f$. Schopenhauer, A., $F M$, p. 224 (§14).

37 En tanto el egoísmo se caracteriza por apuntar siempre al bienestar personal, la crueldad está dirigida al mal ajeno -incluso a costas del bienestar personal-, de manera que mientras en el primero el sufrimiento del otro se presenta como un medio para un fin, en el segundo se presenta como un fin en sí mismo. Por eso Schopenhauer (ibid., p. 226) caracteriza a la raíz de la crueldad como "diabólica", en tanto a la del egoísmo, más "animal".

38 Ibid.

39 Ibid., p. 164 (§6) ["No ofendas a nadie; antes bien, ayuda a todos cuanto puedas"].

40 Ibid., pp. 236-237 (§17).
} 
Ahora bien, el análisis de Schopenhauer no se detiene allí, dado que su último paso consistirá en remitir tales disposiciones al carácter del agente. Se han referido anteriormente las cualificaciones por las que este era definido: individual, empírico, innato e invariable. Se ha mencionado también que nuestro filósofo suele emplear la noción de "carácter" en el sentido de "carácter moral". Paralelamente, hace una afirmación problemática: al ser innato, los fines hacia los que cada individuo tiende están ya invariablemente determinados, de suerte que vicios y virtudes son asimismo disposiciones innatas ("Tugenden und Laster angeboren sind") ${ }^{41}$.

En su óptica, la diversidad ética de los caracteres es increíblemente grande, y está dada por la diferente proporción que asumen en cada uno los tres móviles fundamentales: egoísmo, maldad y compasión ${ }^{42}$. Así como algunos cuerpos reaccionan a los ácidos y otros a los álcalis, cada carácter humano responde a los motivos hacia los que posee mayor sensibilidad ${ }^{43}$. Los motivos altruistas conformarán poderosos estímulos para el buen carácter, pero dejarán indiferente al carácter preponderantemente egoísta, de la misma manera en que la persona receptiva a los motivos malévolos será capaz de llegar a sufrir un gran perjuicio con tal de ocasionar daño a otro.

Por otra parte, ¿qué quiere decir Schopenhauer al afirmar que vicios y virtudes son innatos? En esta dirección, nos dice que ni la prédica de la virtud ni la instrucción moral son capaces de engendrar la bondad de corazón, como así tampoco de pulverizar la maldad del malvado: esta le es tan propia como los colmillos y la bolsa de veneno a la serpiente ${ }^{44}$. En este punto nos topamos con la concepción de virtud que Schopenhauer postula: una concepción bastante estrecha donde queda reducida, presuntamente, a un mero sentir o querer, a una inclinación que puede o no suscitarse según nuestro carácter. Por lo tanto, se posiciona lejos de la visión antigua de areté, al menos de la aristotélica, en cuya óptica la acción virtuosa implicaba un todo más complejo, al presuponer en el agente tanto la recta disposición como correcta deliberación y elección, donde la razón práctica o inteligencia -la prudencia-jugaba un rol preponderante.

41 Cf. Schopenhauer, A., $L V$, p. 84.

${ }^{42}$ Vale la pena advertir que Schopenhauer no piensa que alguno de estos motivos pueda preponderar en forma absoluta. Consiguientemente, no existen en su opinión personas puramente compasivas, o puramente malvadas o egoístas, sino que cada una combina en forma única estas tres disposiciones, aunque sin dudas mostrará mayor inclinación hacia uno u otro de tales motivos. Asimismo, es preciso notar que aquel no establece en qué proporción debería predominar la compasión para que alguien pase a ser considerado un agente virtuoso.

${ }^{43}$ Cf. Schopenhauer, A., FM, p. 279 (§20).

44 Ibid., p. 274. 
Si la virtud es una cuestión de sentimiento, tal como Schopenhauer parece sugerir, entonces la razón no tendría injerencia alguna en nuestra vida moral. Y esta es, en principio, la posición que aparenta defender, al decir por ejemplo que la cualidad de la virtud no procede de la acción sino del amor en la que se origina ${ }^{45}$, o que la moralidad descansa en la bondad del corazón. Para Schopenhauer, ser vicioso y ser racional son cosas perfectamente compatibles ${ }^{46}$. Sin embargo, no es esta su última palabra al respecto, por lo que esta especie de sentimentalismo moral crudo puede ser desafiada o, mejor dicho, matizada, si atendemos a ciertos pasajes decisivos que plantean la importancia inexpugnable de la razón práctica para la moralidad.

En el apéndice al primer tomo de El mundo como voluntad y representación, "Crítica de la filosofia kantiana", Schopenhauer considera el caso de un buen hombre que, a pesar de inclinarse a asistir a los necesitados incluso a expensas del autosacrificio, se muestra siempre reticente a pagar sus deudas -algo así como una persona caritativa pero injusta-. Se trataría este -prosigue nuestro autor- de un carácter irracional, de manera que sería incapaz de perpetrar grandes crimenes, en la medida en que ello presupone la planificación y el disimulo, cosa que lo vuelve incapaz de desarrollar el vicio en grado extremo, esto es, la crueldad premeditada. Sin embargo, y en contrapartida: "será muy dificil que alcance un grado muy alto de virtud, ya que, aun cuando por naturaleza se halle muy inclinado hacia el bien, no pueden faltar los arrebatos puntuales de vicio y maldad a los que cualquier hombre está sometido y que han de convertirse en actos allí donde la razón, mostrándose práctica, no les contraponga máximas inalterables y firmes propósitos"47.

En este pasaje, Schopenhauer insinúa claramente que la mera inclinación al bien no basta para desarrollar en forma consumada la virtud. En otras palabras, la disposición altruista necesita ser complementada con la razón práctica para alcanzar su perfección. Recordemos que él mismo admitía que cada carácter humano combinaba en diferente proporción los motivos de compasión, egoísmo y maldad. Esto significa que incluso los caracteres mayormente proclives a la piedad pueden verse solicitados por impulsos egoístas o malévolos. Luego, es necesario que, en caso de presentarse estos impulsos contrarios a la moralidad, se active en nosotros una fuerza capaz de refrenarlos. Esta fuerza no es otra que la razón, quien a partir de "máximas inalterables" y "firmes

${ }^{45}$ Cf. Schopenhauer, A., MVR I, p. 631.

${ }^{46}$ Ibid., p. 620.

${ }^{47}$ Ibid., p. 623. 
propósitos" contiene y desvía las inclinaciones inconvenientes. Al admitir esta posibilidad, Schopenhauer concede un rol moral indisputable a la razón práctica, quedando su sentimentalismo visiblemente debilitado.

Tal vez esta interpretación desconcierte a más de uno, despertando incluso su desacuerdo. Pues no hay dudas de que la filosofia schopenhaueriana posee un sesgo opuesto al de la tradición racionalista occidental, principalmente por negar la estructuración lógica del mundo y de la psique humana. No es la razón quien nos gobierna, sino una potencia exenta de racionalidad. Con todo, la idea que Schopenhauer parece establecer es la siguiente: si nos dejáramos arrastrar por estas fuerzas maquinales que moran en nosotros, la moralidad dificilmente asomaria y el mundo sería peor de lo que es, porque nadie se privaría de infligir sufrimiento a otros toda vez que la ocasión se presente. Para evitar este escenario fatal, el ser humano posee una capacidad específica: la de abstracción y formación de conceptos y principios, que le permite sobreponerse a la inmediatez y abarcar con una mirada de conjunto el pasado y el futuro. Esta capacidad -que constituye esencialmente a la razón ${ }^{48}$ - le posibilita, precisamente, dominar las inclinaciones inmediatas y actuar en vistas de un propósito.

Si todavía estos argumentos no alcanzan a persuadir al lector, y se resiste a aceptar esta supuesta revalorización de la razón práctica desde un punto de vista moral, consideramos que el siguiente pasaje puede servir para reforzar la interpretación que aquí se está ofreciendo.

Cuando Schopenhauer analiza, en efecto, la virtud de la justicia, deja suficientemente en claro que el uso práctico de la razón, antes que quedar relegado, forma parte de la vida moral en un importante sentido: "Pues, aunque los principios y el conocimiento abstracto en general no son de ningún modo la fuente o el fundamento de la moralidad, a una conducta moral le resultan imprescindibles como el depósito, el réservoir en el que se conserva el ánimo que nace de la fuente de toda moralidad, la cual no fluye en todo momento, para, llegado el caso de la aplicación, fluir a través de canales de derivación... Sin principios firmemente adoptados, quedariamos irresistiblemente a merced de los móviles antimorales cuando éstos son suscitados por impresiones externas en los afectos. La consolidación y seguimiento de los principios a pesar de los motivos que actúan contra ellos es autodominio-[Selbstbeherrschung]-." ${ }^{49}$.

Con estas elocuentes y decisivas palabras, el filósofo de Frankfurt quiere decir, poco más o menos, lo siguiente: como no es dable esperar que la

${ }^{48}$ Ibid., p. 622.

49 Schopenhauer, A., FM, p. 239 (§17).

ARETÉ Revista de Filosofia, vol. XXIX, № 1, 2017 / ISSN 1016-913X 
compasión despierte cada vez que brote en nosotros el impulso de perjudicar a un congénere, es preciso encargar este rol de comando a la razón. Con ello está dando pábulo a la idea de que la moralidad no puede simplemente depender de una cuestión de sentimiento, sobre todo en aquellos casos -como él mismo reconoce- donde la compasión llegaría demasiado tarde (zu spät käme $)^{50}$. En circunstancias donde no se suscitase semejante sentimiento, no habría guía más confiable que la de la propia razón, la cual, venciendo las inclinaciones contrarias, nos conduciría en la dirección correcta. Basta que la compasión haya despertado anteriormente en nosotros, para que la razón, comparando experiencias pasadas con el caso actual, pueda extraer la máxima "neminem laede" -no perjudicar a nadie- y guiarnos en forma resoluta sobre la base de semejante comparación. El uso práctico de la razón, tal como Schopenhauer aquí conviene, se aplica con el objeto especial de evitar acciones injustas, aquellas que, nacidas de inclinaciones egoístas o malvadas, causarian el mal ajeno. Para ser justos, en consecuencia, se requiere haber desarrollado la capacidad de refrenar tales propensiones.

Al admitir la posibilidad de que un principio racional pueda guiar y exhibir en mayor relieve la acción virtuosa, Schopenhauer vuelve a conceder significación a la idea de autodominio (Selbstbeherrschung) ${ }^{51}$ de igual manera en que lo había hecho antes en el contexto de su teoría del carácter adquirido. Es claro el sentido en que el dominio de sí refuerza la virtud del agente: la persona ejercitada en el autodominio, propenderá a ser mayormente justa. Y esto, desde el punto de vista moral, no puede ser indiferente.

50 Ibid., p. 238.

51 Si las (malas) inclinaciones pueden ser refrenadas mediante la contención racional, entonces el carácter no parece ser tan inmodificable como en principio se postula. Este problema es del todo complejo, y nos sitúa de lleno en el problema libertad-determinismo. La posición schopenhaueriana presenta algunas lagunas al respecto, puesto que parte de la tesis determinista según la cual el carácter es innato e inmodificable. De este modo, las acciones de un agente se siguen necesariamente de la confluencia de dos factores: su carácter y un motivo dado. Dentro de este encuadre, Schopenhauer no concede libre albedrío al agente, al describir su accionar como cualquier fenómeno condicionado del mundo natural, sujeto a la ley de causalidad (cuya versión imperante en el mundo animal es la ley de motivación). Sin embargo, su concepción del carácter adquirido desafia en cierta medida ese determinismo recalcitrante, al suponer que un sujeto, al conocer sus disposiciones innatas, es capaz de evitar aquellas situaciones que activan sus malas inclinaciones o elegir, por el contrario, aquellas que activan las buenas. Si ello es así, entonces el accionar de un agente no está enteramente determinado por factores externos a él. En opinión de Atwell (o.c., p. 139), si el sujeto tiene el poder, aunque dentro de ciertos limites, de refrenar sus malas disposiciones evitando la conducta reprobable y la insatisfacción consigo mismo, luego la tesis según la cual el carácter es innato e inalterable tiene, moralmente hablando, poca importancia. 
IV. ¿Es relevante desde un punto de vista moral adquirir carácter?

Más allá de la base sentimental que Schopenhauer confiere a la ética, ello no redunda en una reducción completa de la moralidad al sentimiento. Si la reconstrucción que hemos ofrecido es correcta, la razón jugaría también un importante papel, sobre todo en relación con la virtud de la justicia. Se ha visto que, en semejante ámbito, nuestro autor otorga a la noción de autodominio un lugar incontestable, cosa que presupone la necesaria interferencia de la razón práctica. Su aplicación en la esfera moral -por la que se contiene un impulso mediante el concurso de principios, los cuales posibilitan asimismo la acción conforme a fin- parece ser de la misma indole que aquella envuelta en la adquisición de carácter. Recordemos las palabras que al respecto Schopenhauer pronunciaba: la persona con carácter no sucumbe ante deseos o metas ocasionales que se le presentan y que la arrastran en direcciones opuestas a su modo de ser propio, porque enfrentada a tales circunstancias es capaz "de aplicar principios universales a casos concretos para adoptar una decisión".

De esta suerte, el pensamiento inicial con arreglo al cual nuestro autor afirmaba que adquirir carácter no importa tanto a efectos éticos cuanto prudenciales, puede ser desafiado en sus propios términos. Pues el autodominio requerido para adquirir carácter implica el mismo tipo de habilidad y ejercitación que un sujeto necesita desarrollar para obrar en sentido moral. Podría conjeturarse de este modo que la adquisición de carácter nos entrena también para la práctica virtuosa, en buena medida consistente en el auto-limitarse para no perjudicar a otros. Con arreglo a ello, no sería desatinado afirmar que un sujeto con carácter mostrará mayor predisposición hacia la justicia que un agente que carece de él, justamente por estar mayormente adiestrado en la batalla contra los profusos deseos que lo solicitan. Es factible concluir, entonces, que la persona que adquiere carácter, al desarrollar el mismo tipo de habilidad requerida por la práctica de la justicia, se mostrará menos proclive a perjudicar a los demás. Y esto -no caben dudas- es del todo significativo desde un punto de vista moral.

John Atwell se ha esforzado también por mostrar que la teoria schopenhaueriana del carácter posee resonancias morales ${ }^{52}$. Hasta donde llegamos a ver, serían dos las razones por las que, según este autor, adquirir carácter es moralmente relevante: 1) porque quien se conoce plenamente, es decir, sus propias debilidades morales, intentará eludir los contextos particulares

${ }^{52}$ Cf. Atwell, J., o.c., pp. 135-140.

ARETÉ Revista de Filosofia, vol. XXIX, № 1, 2017 / ISSN 1016-913X 
que activan sus malas disposiciones; 2) porque quien se domina a sí mismo, desarrollará ciertas cualidades de carácter moralmente valiosas, a saber, la diligencia y determinación necesarias para la acción.

Con respecto al primer punto, Atwell señala que la persona que se conoce a sí misma intentará evitar aquellos ambientes poco compatibles con su personalidad, pues sabe que de ese modo se ahorrará momentos desagradables. Luego, es plausible pensar que tal cosa redundaría también en beneficio de otros, porque en atmósferas donde alguien se siente a disgusto, probablemente tienda a comportarse de manera poco apropiada hacia ellos. En esta línea argumentativa se situaría la persona que, al conocer sus debilidades morales, intenta mantenerse alejada de aquellas situaciones que activan sus malas disposiciones. Atwell lo ilustra con ejemplos muy claros: si no nos sentimos bien con nosotros mismos por beber excesivamente, nos mantendremos alejados del Cortina Bar, especialmente los viernes a la noche; si nos avergüenza perder nuestra compostura y decir cosas escandalosas, nos abstendremos de jugar al pool con Joe; y si nos odiáramos a nosotros mismos por cometer adulterio, evitaremos a Cindy ${ }^{53}$. En estos ejemplos se observa que al tiempo de sortearse el descontento personal, se evita el perjuicio que eventualmente podría ocasionarse a otros de activarse esas malas disposiciones. De esta forma, puede argüirse justificadamente que no es irrelevante desde el punto de vista moral que una persona posea carácter en sentido schopenhaueriano. Aunque, claro está, las consideraciones precedentes serían pertinentes para una teoría moral que concediese valor a las consecuencias de las acciones, cosa que Schopenhauer desestima. Consiguientemente, este aspecto indicado por Atwell no puede compatibilizarse con los términos en que el filósofo de la voluntad plantea la teoría ética.

A nuestro parecer, es el segundo aspecto indicado por Atwell el que tiene mayor oportunidad de ser conciliado con la visión schopenhaueriana. En esta dirección -sostiene aquel- sin la firmeza ni determinación necesaria para actuar, la inclinación virtuosa yacería tan oculta en el carácter del agente que dificilmente resultaría exhibida. De igual forma en que el genio artístico permaneceria velado sin la perseverancia ni dedicación constantes requeridas para consumarlo ${ }^{54}$. Si bien la intuición de Atwell es correcta, su interpretación carece de fuerza concluyente al no aportar suficientes elementos de la filosofia de Schopenhauer que la avalen. Con arreglo a ello, consideramos que

53 Ibid., p. 138.

54 Ibid., p. 136.

ARETÉ Revista de Filosofia, vol. XXIX, Nº 1, 2017 / ISSN 1016-913X 
la reconstrucción aquí expuesta puede servir para completar y otorgar mayor plausibilidad a esta línea de interpretación insinuada, aunque no cabalmente desarrollada por el filósofo norteamericano. Precisamente, un aspecto esencial que pasa por alto es el análisis schopenhaueriano de la virtud de la justicia, donde pueden encontrarse valiosos elementos que apuntalan esta linea interpretativa consistente en vindicar el nervio moral de la teoría del carácter adquirido.

Se ha señalado al respecto que, al referirse a la virtud de la justicia, Schopenhauer permite la entrada de la razón práctica en el dominio moral. $\mathrm{Su}$ admisión nos proporciona el elemento que nos faltaba para dar el salto del ámbito prudencial hacia el propiamente moral: pues ambos demandan la capacidad de autodominio, la destreza para inhibir inclinaciones perniciosas mediante la potencia práctica de la razón. En el caso de la esfera prudencial, se trata de las inclinaciones lesivas de la propia felicidad y que la persona con carácter debe refrenar; en el de la esfera moral, de las inclinaciones erosivas del bienestar ajeno y que la persona justa debe cohibir.

\section{Conclusión}

Los desarrollos precedentes han sido estructurados en función de una tesis que hemos procurado defender, a saber: que adquirir carácter en sentido schopenhaueriano no importa exclusivamente desde una perspectiva prudencial sino también moral. La defensa de semejante tesitura nos ha llevado más allá de lo que Schopenhauer explícitamente declara, puesto que, a su juicio, la teoría del carácter adquirido denota tan solo valor eudemonológico o prudencial. Se ha tratado de evidenciar, con todo, que existen elementos en su filosofia que posibilitan una interpretación del tipo propuesto, sin perjuicio de volver su posición inconsistente. Nuestra estrategia ha consistido, en esa dirección, en poner de relieve una noción común a su teoría moral y a su doctrina del carácter adquirido: la de "autodominio", noción que presupone el uso práctico de la razón. Schopenhauer reconoce sin ambages su importancia para la vida mundana -esencialmente orientada a la búsqueda de satisfacción personal- pero se muestra reticente en otorgarle relevancia para la moralidad. Esta circunstancia se explica por su propensión a fundamentarla en el sentimiento, aunque sin reducirla enteramente a ello. Sobre este último aspecto ha dependido fundamentalmente nuestra argumentación y la línea interpretativa aquí enunciada. 
El hecho de que nuestro autor no reduzca la moralidad a una simple cuestión de sentimiento expone su filosofia práctica a una mayor riqueza hermenéutica. Desde el momento en que admite la necesidad de la razón y del autodominio a los efectos de la justicia -una de las virtudes cardinales que su filosofia moral postula-, nos confronta con una suerte de eslabón que unifica los ámbitos de moralidad y prudencia. Al ser esto así, es plausible concluir que la persona que busca perfeccionar su carácter en función del bienestar personal desarrolla el mismo tipo de destreza requerida para obrar justamente. Luego no puede ser indiferente desde el punto de vista moral el que una persona adquiera carácter o no, una vez que Schopenhauer atisba en el autodominio su profunda dimensión ética: sin él, difícilmente se llegaria a ser justo con nuestros semejantes.

Por lo demás, si el tipo de lectura aquí propuesta es correcta, habria buenas razones para enfocar la filosofia práctica schopenhaueriana desde una perspectiva más unitaria, en donde los ámbitos de moralidad y prudencia, de virtud y felicidad, no aparezcan en una disyunción rotunda. Creemos que esta posibilidad de análisis confiere genuina actualidad a su planteo, permitiendo su contribución al debate contemporáneo enmarcado, sobre todo, en la ética de la virtud. Para esta clase de enfoque, solo se puede separar artificialmente la cuestión de la moralidad de la del florecimiento humano, de modo que tanto lo concerniente a la virtud como a la felicidad personal, han de abordarse desde una mirada conjunta. La reconstrucción que aquí se ha ofrecido sobre la perspectiva práctica de Schopenhauer, tiene en lo tocante a ello bastante que aportar.

\section{Bibliografia}

Amaya, A. y H. Hock Lai, Law, Virtue and Justice, Oregon: Hart Publishing, 2013. https:/ / doi.org/10.5040/9781472566294

Atwell, J., Schopenhauer. The Human Character, Filadelfia: Temple University Press, 1990. Cartwright, D., "Schopenhauer's Narrower Sense of Morality", en: Janaway, C. (ed.), The Cambridge Companion to Schopenhauer, Cambridge: Cambridge University Press, 2006. https://doi.org/10.1017/ccol0521621062.009

144 Koßler, M., "Life is But a Mirror: On the Connection Between Ethics, Metaphysics and Character in Schopenhauer", en: Janaway, C. y A. Neil (eds.), Better Consciousness. Schopenhauer's Philosophy of Value, Reino Unido: Blackwell Publishing, 2009. https://doi.org/10.1002/9781444322866.ch6

Long, A., From Epicurus to Epictetus. Studies in Hellenistic and Roman Philosophy, Oxford: The Clarendon Press, 2006. https://doi.org/10.1093/acprof: oso/9780199279128.001.0001 
Schopenhauer, A., Sobre la libertad de la voluntad, en: Schopenhauer, A., Los dos problemas fundamentales de la Ética, traducción, introducción y notas de Pilar López de Santa María, Madrid: Siglo XXI Editores, 2002.

Schopenhauer, A., Sobre el fundamento de la moral, en: Schopenhauer, A., Los dos problemas fundamentales de la Ética, traducción, introducción y notas de Pilar López de Santa María, Madrid: Siglo XXI Editores, 2002.

Schopenhauer, A., El mundo como voluntad y representación, Vol. 1 y 2, traducción, introducción y notas de Roberto Aramayo, Madrid: FCE, 2005.

Schopenhauer, A., Parerga y Paralipomena I, traducción, introducción y notas de Pilar López de Santa María, Madrid: Trotta, 2006.

Séneca, L. A.: "Sobre la serenidad", en: Diálogos, traducción, estudio preliminar y notas de Carmen Codoñer, Barcelona: Altaya, 1997.

Taylor, R., Good and Evil. A Forceful Attack on the Rationalistic Tradition in Ethics, Nueva York: The Macmillan Company, 1970.

Wicks, R., Schopenhauer, Singapore: Blackwell Publishing, 2008. https://doi. org/10.1002/9780470696668

Recibido: 06/01/2015

Aceptado: 30/06/2016 